\title{
Myocardial Perfusion Reserve After a PET-Driven Revascularization Procedure: A Strong Prognostic Factor
}

\author{
Riemer H.J.A. Slart ${ }^{1,2}$, Clark J. Zeebregts ${ }^{2,3}$, Hans L. Hillege ${ }^{4}$, Johan de Sutter ${ }^{5}$, Rudi A.J.O. Dierckx ${ }^{1}$, \\ Dirk J. van Veldhuisen ${ }^{6}$, Felix Zijlstra ${ }^{6}$, and René A. Tio ${ }^{2,6}$ \\ ${ }^{1}$ Department of Nuclear Medicine and Molecular Imaging, University Medical Center Groningen, Groningen, The Netherlands; \\ ${ }^{2}$ Cardiovascular Imaging Group Groningen, University Medical Center Groningen, Groningen, The Netherlands; ${ }^{3}$ Division of Vascular \\ Surgery, Department of Surgery, University Medical Center Groningen, Groningen, The Netherlands; ${ }^{4}$ Department of Epidemiology, \\ University Medical Center Groningen, Groningen, The Netherlands; ${ }^{5}$ Department of Cardiology, AZ Maria Middelares, Ghent, Belgium; \\ and ${ }^{6}$ Department of Cardiology, University Medical Center Groningen, University of Groningen, Groningen, The Netherlands
}

Not all patients treated on the basis of PET-proven viability benefit from revascularization. Myocardial perfusion reserve (MPR) predicts survival in patients not undergoing revascularization. In the present study, we investigated whether MPR is related to survival in ischemic heart disease (IHD) patients after a PET-driven intervention. Methods: Between 1995 and 2003, 119 consecutive patients with chronic IHD underwent a PETdriven revascularization procedure based on ischemia-viability assessment with PET. Patients were followed for all-cause mortality and major cardiovascular events. Results: One hundred nineteen patients underwent a PET-driven revascularization procedure (67 percutaneous coronary interventions, 52 coronary artery bypass grafts) because of angina complaints. The mean age was $67 \pm 11$ y (96 men, 23 women); global left ventricle MPR was $1.54 \pm 0.43$. MPR intertertile boundaries were 1.34 and 1.67. Significantly more cardiac deaths were observed in the lowest and middle MPR tertiles than in the highest tertile. The age- and sex-corrected hazard ratio for the middle tertile was 8.3 (95\% confidence interval, 1.02-68.3) and for the lowest tertile 23.6 (95\% confidence interval, 3.1-179) $(P=0.002)$. After left ventricular ejection fraction (LVEF) and viability were added to the model, MPR remained significant, with hazard ratios of $6.5(0.8-54.4)$ and $18.5(2.3-145.5)(P=0.004)$, whereas neither LVEF nor viability reached significance in this model. Comparable results were found for major adverse cardiac events, with hazard ratios of $3.15(0.82-12.0)$ and $8.24(2.36-28.8)(P=$ 0.002). Conclusion: Patients with IHD revascularized on the basis of PET viability assessment who have a low MPR are at risk for cardiac death and subsequent cardiac events. MPR is a more sensitive predictor for cardiac death than LVEF and extent of viability.

Key Words: positron emission tomography; myocardial perfusion reserve; LV function; coronary artery disease; intervention; long-term outcome

J Nucl Med 2011; 52:873-879

DOI: 10.2967/jnumed.110.084954

Received Nov. 3, 2010; revision accepted Mar. 16, 2011.

For correspondence or reprints contact: René A. Tio, Department of Cardiology, University Medical Center Groningen, University of Groningen, Hanzeplein 1, P.O. Box 30001, 9700 RB, Groningen, The Netherlands.

E-mail: r.a.tio@thorax.umcg.nl

COPYRIGHT @ 2011 by the Society of Nuclear Medicine, Inc.
$\mathbf{P}$ ET is a powerful tool to assess myocardial viability. Therefore, PET is often used in ischemic heart disease (IHD) patients to evaluate which patients should be revascularized. PET has several advantages in this context, because it can be used to simultaneously assess viability, ischemia, and left ventricular function-all important components to guide clinical decision making. It has been shown that patients with viable or hibernating myocardium benefit more from revascularization than those without $(1,2)$. However, when patients were randomized to PET- versus SPECTdriven revascularization (3) or PET-driven revascularization versus care as usual, no clear benefit was found (4). One of the main reasons may have been a low adherence to proto$\mathrm{col}$, as the authors indicated $(3,4)$. On the other hand, other factors may have played a role. In this context, myocardial perfusion reserve (MPR) may be a contributing factor.

The importance of MPR has initially been described in patients with dilated and hypertrophic cardiomyopathy $(5,6)$. In a previous study, we recently extended these observations to patients with end-stage coronary artery disease and reduced left ventricular function (7), showing that MPR is a strong predictor of cardiac events and death. This finding was confirmed by others (8). Until now, it was unknown what the importance of MPR measurements was in patients with IHD amenable to revascularization. One may argue that the revascularization procedure per se will restore epicardial hemodynamics. However, MPR is also determined by microvascular components. Therefore, it would be of clinical importance to evaluate the prognostic value of MPR in IHD patient suitable for revascularization. In the present study, we evaluated whether MPR affected events and mortality in patients with proven hibernating myocardium who subsequently underwent revascularization.

\section{MATERIALS AND METHODS}

\section{Patients and Study Design}

Subjects with advanced IHD who underwent rest ${ }^{13} \mathrm{~N}$-ammonia, dipyridamole stress ${ }^{13} \mathrm{~N}$-ammonia, and gated ${ }^{18} \mathrm{~F}-\mathrm{FDG}$ PET between 1995 and 2003 at the PET center of the University 
Medical Center Groningen for the evaluation of stress-induced ischemia and myocardial viability were eligible. This study prospectively included, with retrospective analysis, 119 subjects who underwent a PET-driven revascularization procedure. Patient data were collected from the hospital information system (Table 1). PET-driven intervention was defined as any cardiac (surgical or percutaneous) procedure performed within the first 6 mo after the PET study date. The revascularization procedure was based on the extent of ischemia and viability. The choice of percutaneous coronary interventions (PCIs) or coronary artery bypass graft (CABG) was based on PET ischemia and viability data and made during the regular meeting of the heart team. These data included the presence of at least $20 \%$ jeopardized myocardium (hibernation or ischemia) in the region supplied by a coronary artery with stenosis (50\%), a cutoff value that has been reported to accurately predict functional improvement of left ventricular function $(3,9)$.

\section{Endpoints}

All causes of mortality were assessed. Cardiac death was defined as sudden death, death after the onset of symptoms suggestive of cardiac ischemia, or death due to heart failure. Cardiac events included cardiac death, myocardial infarction, and nonPET-driven revascularization. Myocardial infarction was defined as an increase in cardiac enzymes ( $>2$ times the upper limit of normal), new pathologic $\mathrm{Q}$ waves on the electrocardiogram, or both. A major adverse cardiac event (MACE) was defined as cardiac death, myocardial infarction, PCI, CABG, or hospitaliza- tion for an acute coronary syndrome or heart failure. Revascularization was considered to be incomplete if not all targeted vessels could be revascularized during the planned procedure or if, during a scheduled follow-up catheterization, restenosis or graft failure was diagnosed.

\section{PET}

The patients underwent dynamic rest ${ }^{13} \mathrm{~N}$-ammonia (400 MBq), dipyridamole stress ${ }^{13} \mathrm{~N}$-ammonia (400 MBq), and gated ${ }^{18} \mathrm{~F}-\mathrm{FDG}$ (200 MBq) PET using a 1-d protocol, as described previously (10). Briefly, PET studies were performed after the patients had discontinued vasoactive medication for 5 plasma half-lives and had refrained from caffeinated beverages for a minimum of $12 \mathrm{~h}$. Imaging was performed with the patient supine and used an ECAT 951 positron camera (Siemens CTI). Thirty-one planes were measured simultaneously over a length of $10.8 \mathrm{~cm}$. The measured resolution of the system was $6 \mathrm{~mm}$ in full width at half maximum. Data were automatically corrected for accidental coincidence and dead time. Patients were positioned with the help of a rectilinear scan. Photon attenuation was measured using a retractable external ring source filled with ${ }^{68} \mathrm{Ge} /{ }^{68} \mathrm{Ga}$. Perfusion imaging was performed after dipyridamole had been infused $(0.56 \mathrm{mg} / \mathrm{kg}$ in $4 \mathrm{~min}$ ). Imaging was started by injecting $400 \mathrm{MBq}$ of ${ }^{13} \mathrm{~N}$-ammonia 6 min after the start of dipyridamole infusion and continued for $15 \mathrm{~min}$. To stimulate ${ }^{18} \mathrm{~F}$-FDG uptake, patients were given $75 \mathrm{~g}$ of glucose orally just before scanning or were given $500 \mathrm{mg}$ of acipimox (Nedios; Byk Pharmaceuticals) orally $90 \mathrm{~min}$ before

TABLE 1

Patient Characteristics for Each Tertile of MPR

\begin{tabular}{|c|c|c|c|c|c|}
\hline Variable & $\begin{array}{l}\text { MPR first tertile } \\
(\leq 1.34)(n=39)\end{array}$ & $\begin{array}{l}\text { MPR second tertile } \\
(1.34-1.69)(n=40)\end{array}$ & $\begin{array}{l}\text { MPR third tertile } \\
(\geq 1.69)(n=40)\end{array}$ & $\begin{array}{c}\text { Total } \\
(n=119)\end{array}$ & $P$ \\
\hline Age $(y)$ & $68 \pm 10$ & $67 \pm 12$ & $66 \pm 10$ & $67 \pm 11$ & 0.52 \\
\hline $\operatorname{Sex}(\mathrm{F} / \mathrm{M})(n)$ & $6 / 34$ & $12 / 26$ & $4 / 36$ & 22/96 & 0.15 \\
\hline Hypercholesterolemia (\%) & 50 & 50 & 35 & 45 & 0.31 \\
\hline Smoking (\%) & 38 & 29 & 30 & 32 & 0.81 \\
\hline Diabetes mellitus (\%) & 28 & 16 & 3 & 15 & 0.010 \\
\hline Hypertension (\%) & 43 & 26 & 35 & 35 & 0.81 \\
\hline Family history (\%) & 43 & 41 & 48 & 44 & 0.52 \\
\hline Previous myocardial infarction (\%) & 85 & 79 & 78 & 81 & 0.97 \\
\hline Previous CABG (\%) & 18 & 24 & 15 & 19 & 0.45 \\
\hline Previous PCl (\%) & 58 & 63 & 35 & 62 & 0.65 \\
\hline LVEF (\%) & $27 \pm 12$ & $34 \pm 17$ & $36 \pm 13$ & $32 \pm 15$ & 0.011 \\
\hline Typical anginal complaints (\%) & 83 & 95 & 93 & 90 & 0.21 \\
\hline LVEDV (mL) & $186 \pm 104$ & $153 \pm 91$ & $120 \pm 83$ & $154 \pm 96$ & 0.007 \\
\hline Aspirin (\%) & 58 & 61 & 78 & 65 & 0.095 \\
\hline Coumadin (\%) & 40 & 40 & 20 & 33 & 0.078 \\
\hline Statin (\%) & 45 & 47 & 35 & 42 & 0.349 \\
\hline Diuretic (\%) & 35 & 37 & 23 & 31 & 0.332 \\
\hline Digoxin (\%) & 20 & 8 & 0 & 9 & 0.007 \\
\hline$\beta$-blocker (\%) & 78 & 71 & 78 & 75 & 0.59 \\
\hline $\begin{array}{l}\text { Angiotensin-converting enzyme inhibitors } \\
\text { or angiotensin receptor blockers (\%) }\end{array}$ & 53 & 58 & 45 & 52 & 0.53 \\
\hline Matching defect (\% left ventricle) & $30 \pm 13$ & $27 \pm 12$ & $25 \pm 16$ & $27 \pm 14$ & 0.23 \\
\hline Mismatching defect (\% left ventricle) & $15 \pm 11$ & $13 \pm 12$ & $11 \pm 10$ & $13 \pm 11$ & 0.34 \\
\hline $\begin{array}{l}\text { Myocardial perfusion at rest } \\
(\mathrm{mL} / \mathrm{min} / 100 \mathrm{~g})\end{array}$ & $94 \pm 21$ & $88 \pm 25$ & $89 \pm 22$ & $90 \pm 22$ & 0.29 \\
\hline Myocardial perfusion during stress & $110 \pm 28$ & $130 \pm 38$ & $177 \pm 46$ & $139 \pm 47$ & 0.0001 \\
\hline
\end{tabular}

(mL/min/100 g)

Categoric variables are shown as percentage (\%) or as number $(n)$, continuous variables as mean \pm SD. 
scanning to lower circulating free fatty acids (11). To prevent side effects of acipimox (e.g., skin rash), $250 \mathrm{mg}$ of aspirin were administered orally $5 \mathrm{~min}$ before acipimox. In diabetic patients, ${ }^{18}$ F-FDG imaging was done with hyperinsulinemic euglycemic glucose clamping (12). After the ${ }^{13} \mathrm{~N}$-ammonia data had been acquired, $200 \mathrm{MBq}$ of ${ }^{18} \mathrm{~F}-\mathrm{FDG}$ were injected intravenously, followed by a PET dynamic acquisition. The total ${ }^{18} \mathrm{~F}$-FDG PET acquisition time was $40 \mathrm{~min}$, with the last $20 \mathrm{~min}$ acquired in gated mode with 16 frames per cardiac cycle. The length of each gate was based on the current R-R interval. The R-R interval was allowed to vary by $\pm 10 \%$. Data were corrected for attenuation using the transmission scan and were reconstructed using filtered backprojection (Hann filter, 0.5 pixels/cycle).

\section{Kinetic Models and Data Analysis}

Dynamic parametric polar maps were constructed from the PET data (10). PET perfusion data at rest were corrected for ratepressure product. Myocardial blood-flow data were corrected for partial-volume effect and spillover and quantified by the model of Hutchins et al. (13). Briefly, myocardial and blood time-activity curves derived from regions of interest over the heart and ventricular chamber are fitted using a 3-compartment model for ${ }^{13} \mathrm{~N}$ ammonia, yielding rate constants for tracer uptake and retention. The perfusion flow reserve (dipyridamole-to-rest ratio) was calculated by dividing the dipyridamole ${ }^{13} \mathrm{~N}$-ammonia stress study by the ${ }^{13} \mathrm{~N}$-ammonia rest study. Data analysis of ${ }^{18} \mathrm{~F}-\mathrm{FDG}$ was performed with Patlak analysis (14). Mismatch was quantified by first normalizing the ${ }^{18} \mathrm{~F}$-FDG uptake polar map and the dipyridamole blood-flow polar map to their means. Then, a difference polar map was created by subtracting the normalized dipyridamole bloodflow polar map from the normalized ${ }^{18} \mathrm{~F}-\mathrm{FDG}$ uptake polar map. Mismatch was calculated as the percentage myocardium above the $95 \%$ confidence interval of the normal database, and results were expressed as percentage of the total myocardium. Similarly, matching areas were quantified by constructing a product polar map; the normalized dipyridamole blood-flow polar map was multiplied by the normalized ${ }^{18} \mathrm{~F}$-FDG uptake polar map. Match was defined as the percentage myocardium below the $95 \%$ confidence interval. The extent of mismatching areas (viable myocardium) and matching areas (nonviable myocardium) was calculated from these data as previously described (10). Using only the stress perfusion images for comparison with ${ }^{18} \mathrm{~F}$-FDG uptake allows identification of jeopardized myocardium but does not allow differentiation between hibernation and ischemia. From a practical point of view, however, this differentiation may not be that important, because both hibernation and ischemia need to undergo revascularization.

The last frames (20-min acquisition time) of the dynamic gated ${ }^{18}$ F-FDG PET studies were summed and transformed into static studies and used for further data analysis with the help of the quantitative gated SPECT program (14). Left ventricular end-systolic and end-diastolic volumes (LVEDV) and left ventricular ejection fraction (LVEF) were computed using the gated ${ }^{18} \mathrm{~F}$-FDG images.

\section{Statistical Analysis}

Descriptive results are expressed as mean \pm SD. Categoric measures are presented as frequencies with percentages. Differences among the 3 tertiles of MPR were assessed by $\chi^{2}$ analysis or ANOVA and tested for trend. The association between MPR and cardiac death or MACE was examined with Cox proportional hazards regression. Crude and age- and sex-adjusted Cox regression-derived relative risks were estimated for cardiac death and MACE. A multiple Cox regression model was developed using bootstrap selection methods (to avoid an overfit model). The variables that correlated with cardiac death at the 0.15 significance level comprised the full model. Such a significance level has previously been suggested (15). Two hundred bootstrap samples were selected; stepwise selection of variables was applied to each sample. The final model consisted only of variables selected in at least $140(70 \%)$ of the bootstrap models, a cutoff value that has been used previously (15). Analyses were performed with SPSS software (version 17.0; SPSS Inc.) and STATA statistical software (release 11.0; StataCorp LP).

\section{RESULTS}

\section{Patient Characteristics}

Between 1995 and 2003, 119 patients underwent a revascularization procedure based on a ${ }^{13} \mathrm{~N}$-ammonia rest,

TABLE 2

Univariate Regression Analysis Risk Estimates for Cardiac Mortality

\begin{tabular}{|c|c|c|c|c|c|c|}
\hline \multirow[b]{2}{*}{ Variable } & \multicolumn{3}{|c|}{ Unadjusted } & \multicolumn{3}{|c|}{ Sex and age adjusted } \\
\hline & Hazard ratio & $\begin{array}{l}95 \% \text { confidence } \\
\text { interval }\end{array}$ & $P$ & Hazard ratio & $\begin{array}{c}95 \% \text { confidence } \\
\text { interval }\end{array}$ & $P$ \\
\hline MPR & 0.79 & $0.70-0.89$ & $<0.001$ & 0.75 & $0.65-0.86$ & $<0.001$ \\
\hline Age & 0.98 & $0.94-1.01$ & 0.184 & & & \\
\hline Sex & 1.13 & $0.39-3.31$ & 0.819 & & & \\
\hline Hypercholesterolemia & 1.15 & $0.52-2.58$ & 0.729 & 1.00 & $0.43-2.31$ & 0.997 \\
\hline Smoking & 1.73 & $0.77-3.90$ & 0.188 & 1.58 & $0.67-3.69$ & 0.294 \\
\hline Diabetes & 3.32 & $1.42-7.77$ & 0.006 & 3.56 & $1.51-8.38$ & 0.004 \\
\hline Hypertension & 1.37 & $0.61-3.08$ & 0.449 & 1.41 & $0.62-3.18$ & 0.414 \\
\hline Positive family history & 0.75 & $0.33-1.72$ & 0.496 & 0.71 & $0.31-1.64$ & 0.42 \\
\hline Previous infarction & 1.16 & $0.40-3.39$ & 0.790 & 1.12 & $0.38-3.31$ & 0.842 \\
\hline Previous PCI & 1.00 & $0.44-2.29$ & 0.999 & 0.95 & $0.41-2.19$ & 0.902 \\
\hline Previous CABG & 1.86 & $0.77-4.49$ & 0.167 & 1.93 & $0.80-4.70$ & 0.144 \\
\hline End-systolic volume & 1.06 & $1.02-1.09$ & 0.001 & 1.06 & $1.02-1.10$ & 0.001 \\
\hline Percentage match & 1.01 & $0.98-1.04$ & 0.407 & 1.00 & $0.98-1.03$ & 0.667 \\
\hline Percentage mismatch & 1.00 & $0.97-1.04$ & 0.884 & 1.00 & $0.97-1.03$ & 0.828 \\
\hline LVEF & 0.79 & $0.67-0.93$ & 0.005 & 0.78 & $0.66-0.93$ & 0.005 \\
\hline
\end{tabular}


TABLE 3

Bootstrapping Results

\begin{tabular}{lcc}
\hline \multicolumn{1}{c}{ Variable } & $\begin{array}{c}\text { Frequencies for } \\
\text { cardiac death }\end{array}$ & $\begin{array}{c}\text { Frequencies } \\
\text { for MACE }\end{array}$ \\
\hline MPR & 189 & 198 \\
End-systolic volume & 101 & 126 \\
LVEF & 26 & 19 \\
Diabetes & 72 & 121
\end{tabular}

Bootstrap results of all variables are presented. Variables that correlated with cardiac death at 0.15 significance level comprised full model. Two hundred bootstrap samples were selected; stepwise selection of variables was applied to each sample. Final model consisted of only variables selected in at least $140(70 \%)$. dipyridamole stress, and gated ${ }^{18}$ F-FDG PET scan. Sixtyseven patients underwent PCI, and 52 underwent CABG. Patient characteristics are shown in Table 1. Ten percent of the patients were in New York Heart Association class I, $44 \%$ in class II, $37 \%$ in class III, and $9 \%$ in class IV. Overall, the MPR was $1.54 \pm 0.43$ (intertertile boundaries, 1.34 and 1.69). Areas of mismatch were found in 81 patients (68\%), areas of matching defects in $116(96 \%)$, and both mismatching and matching defects in $79(66 \%)$. Mean percentage match in the study group was $27 \% \pm 14 \%$, mean percentage mismatch was $13 \% \pm 11 \%$, and mean LVEF was $32 \% \pm 15 \%$. Coronary artery disease was present in the left anterior descending artery in $81 \%$ of patients, in the right coronary artery in $58 \%$, and in the circumflex coronary artery in $42 \%$. Significant differences between the 3 MPR tertiles were present for LVEF, LVEDV, and digoxin
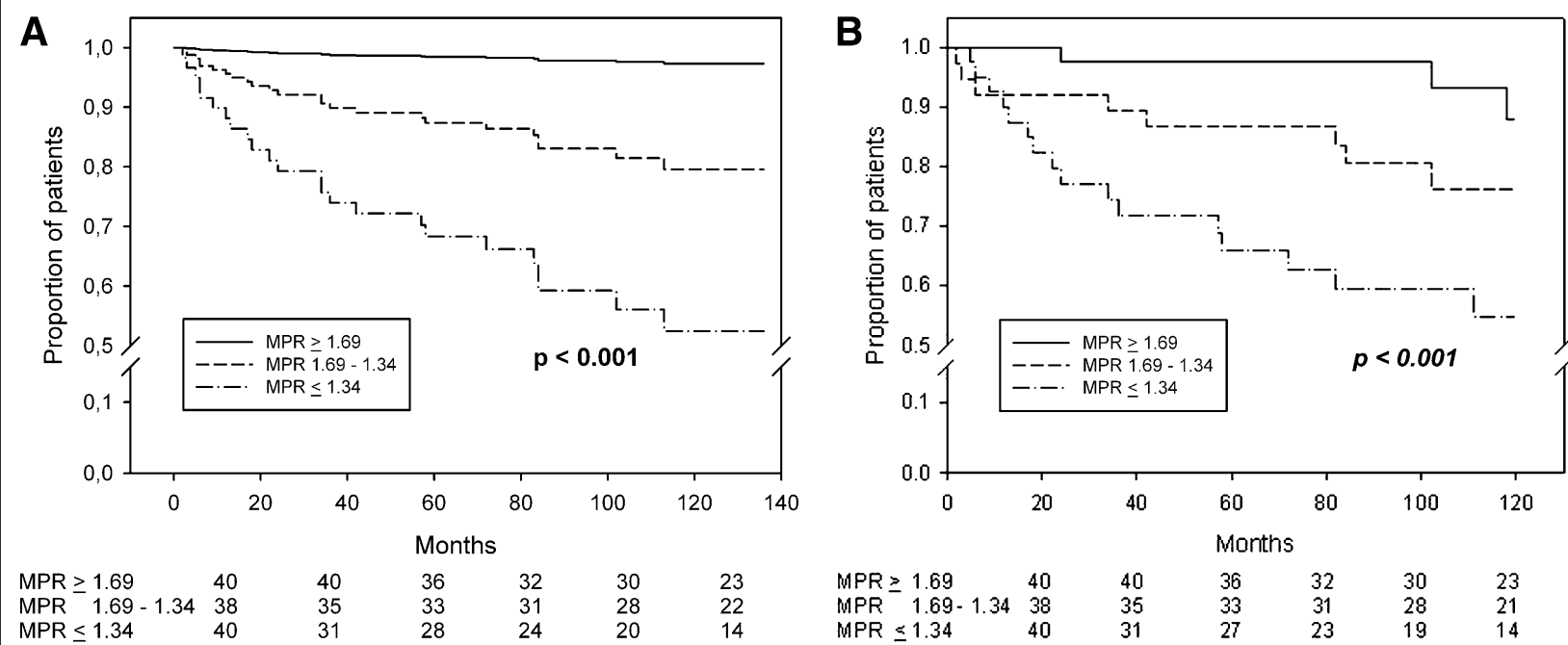

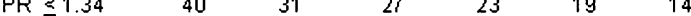
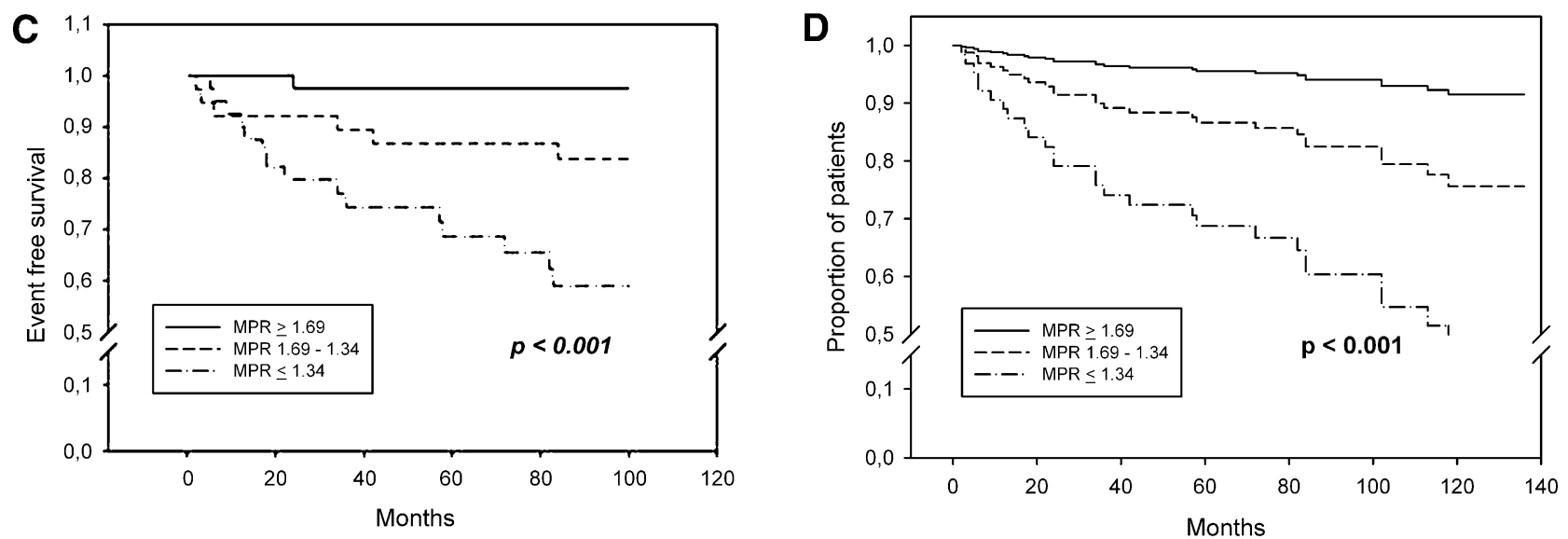

$\begin{array}{llllll}\text { MPR } \geq 1.69 & 40 & 40 & 36 & 32 & 30 \\ \text { MPR } 1.69-1.34 & 38 & 35 & 33 & 31 & 28 \\ \text { MPR } \leq 1.34 & 40 & 31 & 28 & 24 & 20\end{array}$

FIGURE 1. Kaplan-Meier plot for cardiac mortality (A) and for MACE (B) of MPR tertiles and age- and sex-adjusted plots (C and D, respectively) are shown. Median MPR values of each tertile (intertertile boundaries, 1.34 and 1.69) were taken to illustrate differences between these groups. Numbers indicate patients at risk per tertile. Log rank statistics are presented for equality of survival distributions for different tertiles. Data were unadjusted for risk factors. 
use. Baseline perfusion was comparable; differences in stress perfusion apparently contributed to the MPR.

\section{Outcome Events}

The median follow-up among survivors was 88 mo (range, 1-134 mo). Among the 119 patients in this study, there were a total of 29 deaths (24\%), of which $22(18 \%)$ were cardiac deaths. Six patients $(5 \%)$ experienced a nonfatal myocardial infarction. A total of 24 patients $(20 \%)$ underwent a non-PET-driven PCI and 5 a CABG (4\%) during follow-up.

\section{MPR and Cardiac Death}

Table 2 summarizes the results of the Cox regression analysis for cardiac death. In the univariate analysis, both LVEF and MPR and end-systolic volume and diabetes had a significant association with cardiac death - an association that remained after adjustment for age and sex. The frequencies obtained after bootstrapping are shown in Table 3. In the final model, only MPR remained significant, with a hazard ratio of $0.79(0.70-0.89 ; P<0.001)$, whereas neither LVEF nor viability reached significance in this model.

In addition to viability and extent of mismatch, the success of revascularization was also considered. In 24 of the 119 patients, revascularization was considered incomplete. No differences regarding incomplete revascularization were observed between the 3 tertiles $(8,9$, and 7 patients, respectively). Completeness of revascularization did not influence the prognostic value of MPR.

Survival data for each MPR tertile are shown in Figure 1A.

\section{MPR and MACE}

Table 4 summarizes the results of the age- and sexadjusted Cox regression analysis for MACE. In the univariate analysis, the parameters significantly associated with cardiac death were MPR, diabetes mellitus, LVEF, and
LVEDV. The frequencies obtained after bootstrapping are shown in Table 3 . The final model included only MPR, with a hazard ratio of $0.84(0.75-0.95 ; P=0.004)$. None of the other variables reached significance.

In the lowest and middle MPR tertiles, significantly more MACE were observed than in the highest tertile (Fig. 1B).

\section{DISCUSSION}

Since the identification of hibernating myocardium (16), many PET studies have been performed to assess viability (1,2,4,17-19). Besides PET, other imaging modalities may yield diagnostic information on viability $(3,20,21)$. The advantage of PET is that on top of viability, absolute myocardial perfusion can be measured. In addition, MPR can be assessed using vasodilator substances. In the present study, we further expand our previous data (7) to revascularization patients. Interestingly, despite the intervention, MPR remains a strong predictor of survival also in this group, implying that even after restoration of epicardial hemodynamics, preintervention microvascular dynamics remain important. Regional MPR has previously been investigated in a study using MRI $24 \mathrm{~h}$ after PCI. In that study, it was shown that regional MPR improved after PCI but did not normalize and that improvement of MPR was better after stenting than after balloon angioplasty (22). In another study using MRI to assess regional MPR early and late after PCI, it was shown that the initial drop in MPR recovered after 6 mo. These authors argued that the extent of distal embolization may have temporally negatively influenced regional MPR (23). In our intervention group, more than half of the patients underwent a PCI. As MPR can be assessed repeatedly because of its noninvasive nature, it has been suggested as a tool for monitoring effects of risk factor modification such as lipid-lowering treatment (24). Whether this translates into improved risk modification and

TABLE 4

Univariate Regression Analysis for MACE

\begin{tabular}{|c|c|c|c|c|c|c|}
\hline \multirow[b]{2}{*}{ Variable } & \multicolumn{3}{|c|}{ Unadjusted } & \multicolumn{3}{|c|}{ Sex and age adjusted } \\
\hline & Hazard ratio & $\begin{array}{l}95 \% \text { confidence } \\
\text { interval }\end{array}$ & $P$ & Hazard ratio & $\begin{array}{c}95 \% \text { confidence } \\
\text { interval }\end{array}$ & $P$ \\
\hline MPR & 0.79 & $0.70-0.89$ & $<0.001$ & 0.96 & $0.92-0.99$ & 0.021 \\
\hline Age & 0.98 & $0.94-1.01$ & 0.184 & & & \\
\hline Sex & 1.13 & $0.39-3.32$ & 0.819 & & & \\
\hline Hypercholesterolemia & 1.15 & $0.51-2.58$ & 0.729 & 0.98 & $0.94-1.01$ & 0.211 \\
\hline Smoking & 1.73 & $0.77-3.90$ & 0.188 & 1.58 & $0.67-3.69$ & 0.294 \\
\hline Diabetes & 3.32 & $1.42-7.77$ & 0.006 & 3.56 & $1.51-8.38$ & 0.004 \\
\hline Hypertension & 1.37 & $0.61-3.09$ & 0.449 & 1.41 & $0.62-3.18$ & 0.414 \\
\hline Positive family history & 0.75 & $0.33-1.72$ & 0.496 & 0.71 & $0.31-1.63$ & 0.420 \\
\hline Previous infarction & 1.16 & 0.40-3.39 & 0.79 & 1.12 & $0.38-3.31$ & 0.842 \\
\hline Previous $\mathrm{PCl}$ & 1.00 & $0.44-2.29$ & 0.999 & 0.95 & $0.41-2.19$ & 0.902 \\
\hline Previous CABG & 1.86 & $0.77-4.49$ & 0.167 & 1.93 & $0.80-4.70$ & 0.144 \\
\hline End-systolic volume & 1.06 & $1.02-1.09$ & 0.001 & 1.06 & $1.02-1.10$ & 0.001 \\
\hline Percentage match & 1.01 & $0.98-1.04$ & 0.407 & 1.00 & $0.98-1.03$ & 0.667 \\
\hline Percentage mismatch & 1.00 & $0.97-1.04$ & 0.884 & 1.00 & $0.97-1.04$ & 0.828 \\
\hline LVEF & 0.79 & $0.67-0.93$ & 0.005 & 0.78 & $0.66-0.93$ & 0.005 \\
\hline
\end{tabular}


prognostic benefit remains to be elucidated. In a small number of patients undergoing a second PET scan after revascularization, we did not find improved MPR (data not shown). The question remains whether epicardial revascularization has a large effect on the small vasculature. LVEF in our study was low and, as can be expected, did not discriminate with respect to prognosis. Apparently, MPR on top of a low LVEF can be used to further determine prognosis in these patients.

We have previously described the relationship between myocardial perfusion and (regional) left ventricular function $(25,26)$ in heart failure patients. The importance of myocardial perfusion and further development of heart failure as a result of this phenomenon has also been proposed $(27,28)$. In heart failure patients with coronary artery disease, the decision on whether to revascularize depends at present on viability (besides coronary anatomy). The present study sheds new light on the revascularization issue: microvascular function also matters. According to the guidelines, revascularization in patients with heart failure should be considered in selected heart failure patients with coronary artery disease. At present, myocardial perfusion (reserve) is not considered in the decision process (29). The overall 5-y event rate in the 2 higher MPR tertiles was better than the recently published BARI-2D data (30), and in the middle tertile, these results are comparable to the long-term survival in the original BARI study group (31). The lower tertile, however, showed a much higher 5-y event.

Our study has several limitations. We did not analyze regional perfusion defects, possibly leading to a dilution of the data. In our patients with known coronary artery disease, an even higher predictive value of regional MPR might be expected. Furthermore, as a result of the large time span during which patients were included, medication regimens and guidelines have been subject to change. The low percentage of patients on angiotensin-converting enzyme inhibitors or angiotensin receptor blockers can be considered a result of this lengthy time span.

Finally, we did not randomize patients according to MPR. However, because these data are the reflection of standard clinical care we feel this is an important observation adding to recent previous observations $(7,8)$.

\section{CONCLUSION}

The extent of mismatch is a good predictor of functional recovery (2). It has also been shown that prognosis can be assessed by preoperative viability assessment (17). As such, one could argue that a diagnostic work-up to identify patients who would benefit most from revascularization should include viability assessment. In a randomized trial comparing PET-guided care with standard care, no significant benefit was found (4). It has been suggested that the major explanation for the lack of benefit shown in this study may be found in the large proportion of patients who did not adhere to the PET-indicated strategy $(2,32)$, because a post hoc analysis showed $38 \%$ fewer events in patients who adhered to the PET recommendations. Our data shed light on another aspect in this patient group. Despite the PETdriven revascularization procedure, the group with the lower MPR did worse: viability combined with MPR-guided strategy may better select patients who will optimally benefit from revascularization. Finally, it would be worthwhile to pursue interventions aiming at improvement or maintenance of coronary vascular function $(33,34)$.

\section{DISCLOSURE STATEMENT}

The costs of publication of this article were defrayed in part by the payment of page charges. Therefore, and solely to indicate this fact, this article is hereby marked "advertisement" in accordance with 18 USC section 1734.

\section{REFERENCES}

1. Allman KC, Shaw LJ, Hachamovitch R, Udelson JE. Myocardial viability testing and impact of revascularization on prognosis in patients with coronary artery disease and left ventricular dysfunction: a meta-analysis. J Am Coll Cardiol. 2002;39:1151-1158.

2. Beanlands RS, Ruddy TD, deKemp RA, et al. Positron emission tomography and recovery following revascularization (PARR-1): the importance of scar and the development of a prediction rule for the degree of recovery of left ventricular function. J Am Coll Cardiol. 2002;40:1735-1743.

3. Siebelink HM, Blanksma PK, Crijns HJ, et al. No difference in cardiac event-free survival between positron emission tomography-guided and single-photon emission computed tomography-guided patient management: a prospective, randomized comparison of patients with suspicion of jeopardized myocardium. $J \mathrm{Am}$ Coll Cardiol. 2001;37:81-88.

4. Beanlands RS, Nichol G, Huszti E, et al. F-18-fluorodeoxyglucose positron emission tomography imaging-assisted management of patients with severe left ventricular dysfunction and suspected coronary disease: a randomized, controlled trial (PARR-2). J Am Coll Cardiol. 2007;50:2002-2012.

5. Cecchi F, Olivotto I, Gistri R, Lorenzoni R, Chiriatti G, Camici PG. Coronary microvascular dysfunction and prognosis in hypertrophic cardiomyopathy. N Engl J Med. 2003;349:1027-1035.

6. Neglia D, Michelassi C, Trivieri MG, et al. Prognostic role of myocardial blood flow impairment in idiopathic left ventricular dysfunction. Circulation. 2002; 105:186-193.

7. Tio RA, Dabeshlim A, Siebelink HM, et al. Comparison between the prognostic value of left ventricular function and myocardial perfusion reserve in patients with ischemic heart disease. J Nucl Med. 2009;50:214-219.

8. Herzog BA, Husmann L, Valenta I, et al. Long-term prognostic value of ${ }^{13} \mathrm{~N}$ ammonia myocardial perfusion positron emission tomography added value of coronary flow reserve. J Am Coll Cardiol. 2009;54:150-156.

9. Bax JJ, Visser FC, Elhendy A, et al. Prediction of improvement of regional left ventricular function after revascularization using different perfusion-metabolism criteria. J Nucl Med. 1999;40:1866-1873.

10. Blanksma PK, Willemsen ATM, Meeder JG, et al. Quantitative myocardial mapping of perfusion and metabolism using parametric polar map displays in cardiac PET. J Nucl Med. 1995;36:153-158.

11. Knuuti MJ, Yki-Jarvinen H, Voipio-Pulkki LM, et al. Enhancement of myocardial [fluorine-18] fluorodeoxyglucose uptake by a nicotinic acid derivative. $\mathrm{J} \mathrm{Nucl}$ Med. 1994;35:989-998.

12. Knuuti MJ, Nuutila P, Ruotsalainen U, et al. Euglycemic hyperinsulinemic clamp and oral glucose load in stimulating myocardial glucose utilization during positron emission tomography. J Nucl Med. 1992;33:1255-1262.

13. Hutchins GD, Schwaiger M, Rosenspire KC, Krivokapich J, Schelbert H, Kuhl DE. Noninvasive quantification of regional blood flow in the human heart using N-13 ammonia and dynamic positron emission tomographic imaging. J Am Coll Cardiol. 1990;15:1032-1042.

14. Gambhir SS, Schwaiger M, Huang SC, et al. Simple noninvasive quantification method for measuring myocardial glucose-utilization in humans employing positron emission tomography and F-18 deoxyglucose. J Nucl Med. 1989;30:359-366.

15. Orford JL, Lennon R, Melby S, et al. Frequency and correlates of coronary stent thrombosis in the modern era: analysis of a single center registry. J Am Coll Cardiol. 2002;40:1567-1572. 
16. Rahimtoola SH. The hibernating myocardium. Am Heart J. 1989;117:211-221.

17. Haas F, Haehnel CJ, Picker W, et al. Preoperative positron emission tomographic viability assessment and perioperative and postoperative risk in patients with advanced ischemic heart disease. J Am Coll Cardiol. 1997;30: 1693-1700.

18. Tamaki N, Kawamoto M, Tadamura E, et al. Prediction of reversible ischemia after revascularization: perfusion and metabolic studies with positron emission tomography. Circulation. 1995;91:1697-1705.

19. Tillisch J, Brunken R, Marshall R, et al. Reversibility of cardiac wall-motion abnormalities predicted by positron tomography. N Engl J Med. 1986;314:884888.

20. Bax JJ, Cornel JH, Visser FC, et al. Prediction of recovery of myocardial dysfunction after revascularization: comparison of fluorine-18 fluorodeoxyglucose/ thallium-201 SPECT, thallium-201 stress-reinjection SPECT and dobutamine echocardiography. J Am Coll Cardiol. 1996;28:558-564.

21. Schinkel AF, Bax JJ, Poldermans D. Clinical assessment of myocardial hibernation. Heart. 2005;91:111-117.

22. Al Saadi N, Nagel E, Gross M, et al. Improvement of myocardial perfusion reserve early after coronary intervention: assessment with cardiac magnetic resonance imaging. J Am Coll Cardiol. 2000;36:1557-1564.

23. Selvanayagam JB, Cheng AS, Jerosch-Herold M, et al. Effect of distal embolization on myocardial perfusion reserve after percutaneous coronary intervention: a quantitative magnetic resonance perfusion study. Circulation. 2007;116:14581464.

24. Guethlin M, Kasel AM, Coppenrath K, Ziegler S, Delius W, Schwaiger M. Delayed response of myocardial flow reserve to lipid-lowering therapy with fluvastatin. Circulation. 1999;99:475-481.

25. Tio RA, Slart RH, de Boer RA, et al. Reduced regional myocardial perfusion reserve is associated with impaired contractile performance in idiopathic dilated cardiomyopathy. Neth Heart J. 2009;17:470-474.
26. van den Heuvel AF, van Veldhuisen DJ, van der Wall EE, et al. Regional myocardial blood flow reserve impairment and metabolic changes suggesting myocardial ischemia in patients with idiopathic dilated cardiomyopathy. $J$ Am Coll Cardiol. 2000;35:19-28.

27. de Boer RA, Pinto YM, van Veldhuisen DJ. The imbalance between oxygen demand and supply as a potential mechanism in the pathophysiology of heart failure: the role of microvascular growth and abnormalities. Microcirculation. 2003;10:113-126.

28. van Veldhuisen DJ, van den Heuvel AF, Blanksma PK, Crijns HJ. Ischemia and left ventricular dysfunction: a reciprocal relation? J Cardiovasc Pharmacol. 1998;32(suppl 1):S46-S51.

29. Dickstein K, Cohen-Solal A, Filippatos G, et al. ESC guidelines for the diagnosis and treatment of acute and chronic heart failure 2008: the Task Force for the Diagnosis and Treatment of Acute and Chronic Heart Failure 2008 of the European Society of Cardiology. Developed in collaboration with the Heart Failure Association of the ESC (HFA) and endorsed by the European Society of Intensive Care Medicine (ESICM). Eur J Heart Fail. 2008;10:933-989.

30. Frye RL, August P, Brooks MM, et al. A randomized trial of therapies for type 2 diabetes and coronary artery disease. $N$ Engl J Med. 2009;360:2503-2515.

31. Holmes DR Jr, Kim LJ, Brooks MM, et al. The effect of coronary artery bypass grafting on specific causes of long-term mortality in the Bypass Angioplasty Revascularization Investigation. J Thorac Cardiovasc Surg. 2007;134:38-46.

32. Gould KL. Not all randomized trials are equal. J Am Coll Cardiol. 2007; 50:2013-2015.

33. Schindler TH, Cadenas J, Facta AD, et al. Improvement in coronary endothelial function is independently associated with a slowed progression of coronary artery calcification in type 2 diabetes mellitus. Eur Heart J. 2009;30:3064-3073.

34. Schindler TH, Campisi R, Dorsey D, et al. Effect of hormone replacement therapy on vasomotor function of the coronary microcirculation in post-menopausal women with medically treated cardiovascular risk factors. Eur Heart J. 2009; 30:978-986. 